\title{
Phenotypic and genotypic properties of the genus Hafnia
}

\author{
J. MICHAEL JANDA, SHARON L. ABBOTT, SHIDEH KHASHE and WILL PROBERT
}

Microbial Diseases Laboratory, Division of Communicable Disease Control, California Department of Health Services, Berkeley, CA 94704-1011, USA

\begin{abstract}
The present study characterised 73 Hafnia alvei isolates and five Escherichia isolates (originally identified as $\mathrm{H}$. alvei) isolated from cases of diarrhoeal disease by the International Centre for Diarrhoeal Disease Research Branch (ICDDRB) in Bangladesh. Based upon the hydrolysis of arbutin and aesculin and the fermentation of salicin and D-arabinose, four distinct biotypes could be recognised among the $73 \mathrm{H}$. alvei isolates tested; biotype 1 (D-(-)-arabinose-positive only) accounted for $75 \%$ of all isolates analysed. Hydrolysis of aglycone compounds such as arbutin, salicin and aesculin appeared to be associated with expression of $\beta$-glucosidase activity. ICDDRB isolates, when compared with type or reference strains of $H$. alvei, were shown not to belong to the genus Hafnia based upon resistance to Hafnia-specific bacteriophage 1672, possession of the phoE gene, expression of glutamate decarboxylase activity and significant $16 \mathrm{~S}$ rDNA sequence divergence $(\sim 8 \%)$ from the type strain, ATCC $13337^{\mathrm{T}}$. True $H$. alvei strains, implicated in outbreaks of diarrhoeal disease in Canada, lacked the eae $A$ gene in contrast to ICDDRB isolates. Twenty-two $\mathrm{H}$. alvei isolates were selected for further study. Based upon partial 16S rDNA sequencing, these 22 isolates fell into two genomic groups (genomospecies), identical to DNA groups previously established by DNA hybridisation studies. Markers such as motility, biotype, or enzymic or carbohydrate fermentation patterns did not correlate totally with DNA grouping, although malonate utilisation appeared to be the single best discriminatory phenotype. The results indicate that the genus Hafnia is heterogeneous and there do not appear to be any laboratory data available specifically linking these organisms to gastro-enteritis.
\end{abstract}

\section{Introduction}

The genus Hafnia was first recognised by Møeller [1] almost 50 years ago while studying amino acid decarboxylase patterns in members of the family Enterobacteriaceae. Møeller named this new group the 'Hafnia group'. Distinguishing phenotypic features of this taxon included a positive Voges-Proskauer reaction, production of lysine and ornithine decarboxylases, and a negative arginine dihydrolase test. Over the intervening years, the correct taxonomic position of these bacteria has been the subject of considerable controversy and a proposal to include them within the genus Enterobacter as either Ent. alvei, Ent. hafniae or a subspecies of Ent. aerogenes has been made [2].

Received 7 Dec. 2001; revised version accepted 4 March 2002.

Corresponding author: Dr J. M. Janda (e-mail: jjanda@dhs. ca.gov).
However, DNA hybridisation studies conducted by Steigerwalt and colleagues [3] found that Ent. hafniae was not closely related to other Enterobacter species (18-22\% relatedness). Thus, the genus Hafnia as described by Møeller [1] is a legitimate taxon with a single recognised species, $H$. alvei [2]. A second conclusion drawn from the study of Steigerwalt et al. [3] was the apparent fact that multiple genomospecies existed within the genus. This observation led to subsequent DNA relatedness studies by Brenner [4] that confirmed the existence of at least two DNA groups within $H$. alvei. Unfortunately, these DNA groups cannot be clearly separated from one another by conventional biochemical tests. In addition to multiple genomic species, several rare biogroups of $H$. alvei have been described $[4,5]$.

The clinical importance of $H$. alvei is presently unclear, although it is unquestionably an opportunist pathogen in debilitated hosts [6]. Recently, Albert and others 
$[7,8]$ described a number of ' $H$. alvei-like' isolates from the diarrhoeal stools of Bangladeshi children $<5$ years of age. This link between $H$. alvei and bacterial gastro-enteritis has fuelled a series of case reports documenting $H$. alvei as a gastro-intestinal pathogen [9-11]. One problem with this association is the continued accumulation of phylogenetic, molecular and phenotypic evidence that these ' $H$. alvei-like' isolates are either extremely aberrant $H$. alvei isolates or possibly members of the genus Escherichia $[12,13]$.

There have been no large taxonomic studies of $H$. alvei since the report of Greipsson and Priest [14]. In light of the genomic heterogeneity within the nomenspecies $H$. alvei and its suggested association with diarrhoeal disease, a large collection of hafniae was characterised on a phenotypic and genotypic basis. These investigations are the basis of this report.

\section{Materials and methods}

\section{Bacterial strains and bacteriophage}

A total of $73 \mathrm{H}$. alvei isolates from the Microbial Diseases Laboratory was investigated. They were identified to genus and species level by conventional biochemical tests as described previously [15]. Included in these 73 isolates were reference strains ATCC 13337 (DNA group 1), ATCC 29926 (DNA group 1), ATCC 29927 (DNA group 2), all obtained from the American Type Culture Collection (Manassas, VA, USA) and CCUG 429 from the Culture Collection of the University of Göteborg, Sweden. Strains D46-NF and D67-NF, implicated in two outbreaks of diarrhoeal disease attributed to $H$. alvei $[9,16]$ were provided by A. Ismaili (Department of Microbiology, University of Toronto). Five other 'Hafnia-like' strains (ICDDRB strains 9194, 10457, 10790, 12502, 19982), previously obtained from and reported by Albert et al. [7, 8] were included for comparative purposes. The Hafnia-specific bacteriophage 1672 , originally isolated by Guinée and Valkenburg [17], was obtained from ATCC (ATCC 51873-B1).

\section{Phenotypic studies}

$H$. alvei biotypes were determined on the basis of the hydrolysis of aesculin and arbutin $(48 \mathrm{~h})$ and the fermentation of D-arabinose, salicin, lactose, raffinose and adonitol $(72 \mathrm{~h})$. Fermentation reactions were determined in extract broth (Acumedia Manufacturers, Baltimore, MD, USA) containing Andrades' indicator. Some Hafnia isolates were also tested for glutamate decarboxylase activity by the method of Rice et al. [18]. Motility was assessed in motility deeps after $24 \mathrm{~h}$ and by determining the zone of migration $(\mathrm{mm})$ in chemotactic agar plates [19]. The presence of preformed esterases, aminopeptidases, proteases, phosphatases and glycosidases was evaluated with API ZYM strips according to the manufacturer's instructions [20]; production of $\alpha$-glucosidase and $\beta$-glucosidase was also determined with Wee-Tabs (Key Scientific, Round Rock, TX, USA). Alkylsulphatase, cellulase, chitinase, deoxyribonuclease, elastase, lecithinase, mucinase, protease, ribonuclease, siderophore, stapholysin and tyrosinase activities were determined in plate assays as described previously [20-22]. Susceptibility to Hafniaspecific bacteriophage 1672 was performed on nutrient agar quadrant plates with tryptone broth-grown suspensions of test organisms [17].

\section{Genotypic studies, pathogenicity assays and animal studies}

Pulsed-field gel electrophoresis (PFGE) of chromosomal DNA and detection of eaeA, stxl, stx2 and phoE by PCR were performed as described previously [13]. Bacterial adhesins, invasins and cytotoxins were detected with HEp-2 cells $[23,24]$. The relative pathogenicity of selected Hafnia and Hafnia-like isolates was assessed by determining the $50 \%$ lethal dose (LD50) for each isolate in Swiss-Webster mice by intraperitoneal injection [25]. Animal studies were conducted under the supervision and approval of the Institutional Animal Care and Use Committee, California Department of Health Services (protocol 00-14). Partial 16S rDNA sequencing of selected isolates was performed with an Applied Biosystems ABI 377 sequencer, and sequence assembly and analysis were accomplished with MicroSeq Analysis software [26]. Hafnia isolates were assigned to either DNA group 1 or 2 if there was $<0.5 \% 16 \mathrm{~S}$ rDNA sequence divergence between the test isolate and the reference strain for a given genomospecies (ATCC 13337, ATCC 29927).

\section{Results}

\section{H. alvei biotypes}

Barbe described two biotypes of Hafnia based upon aesculin and arbutin hydrolysis and the fermentation of D-arabinose and salicin [cited in 4]. Of the $73 \mathrm{H}$. alvei isolates tested, $75 \%$ fell into Barbe biotype 1 (Table 1). Biotype 2 isolates, characterised by the hydrolysis of aesculin and arbutin, and the fermentation of salicin, were less common. Two new biotypes, designated Barbe biotypes 3 and 4, were encountered in this survey. Biotype 3 isolates were positive for the hydrolysis of aesculin and arbutin and acid production from the fermentation of salicin and D-arabinose. Biotype 4 isolates lacked activity against these glycosides and failed to ferment salicin and D-arabinose. Together they comprised only $10 \%$ of the isolates studied. As arbutin, aesculin and salicin are the most common aglycone compounds (glycosides) that bacteria can utilise, Barbe biotype 2 and 3 isolates were investigated further with other aglycone compounds. All 13 aesculin-positive isolates failed to ferment two other aglycone compounds, amygdalin and $\alpha$-methylD-glucoside, although they produced acid from the 
Table 1. Barbe biotypes of $H$. alvei

\begin{tabular}{lccccc}
\hline \multicolumn{4}{c}{ Biochemical reactions } & Number (\%) \\
\cline { 2 - 5 } Biotype & Aesculin & Arbutin & Salicin & D-(-)-Arabinose & of isolates \\
\hline 1 & - & - & - & + & $55(75)$ \\
2 & + & + & + & - & $11(15)$ \\
$3^{*}$ & + & + & + & + & $2(3)$ \\
$4^{*}$ & - & - & - & - & $5(7)$ \\
\hline
\end{tabular}

*As defined in this report.

fermentation of $\beta$-methyl-D-glucoside; eight aesculinnegative $H$. alvei isolates produced similar results. However, in rapid Wee-Tab enzymic assays, 11 of 13 aesculin-positive isolates produced both $\alpha$ - and $\beta$ glucosidases; in contrast, only 3 of 8 aesculin-negative $H$. alvei isolates produced $\beta$-glucosidase and none elaborated $\alpha$-glucosidase. A second biotype or taxon of H. alvei has been described by Gavini et al. [27] on the basis of the rapid fermentation of lactose, raffinose and adonitol. Most isolates (95\%) failed to ferment rapidly any of these three carbohydrates but four isolates fermented either lactose or raffinose or both rapidly; two of the latter isolates were from urine; the clinical source of the other two isolates was unknown. None of the $73 \mathrm{H}$. alvei isolates fermented adonitol.

\section{Diarrhoea-associated H. alvei}

The ICDDRB strains of Albert et al. [7, 8], previously linked to diarrhoeal disease, were compared to type or reference strains of $H$. alvei (Table 2). ICDDRB strains possessed atypical biochemical properties for inclusion in the genus [13], were not susceptible to lysis by Hafnia-specific phage 1672 and were E. coli phoEpositive [13]. They also produced a ladder-like DNA pattern of high and low mol. wt bands by PFGE when cut with $X b a \mathrm{I}$. All five ICDDRB strains produced glutamate decarboxylase (GAD), a characteristic associated only with E. coli and some Shigella strains in the family Enterobacteriaceae [18]. In contrast, all three reference strains of $H$. alvei were susceptible to phage 1672, were phoE-negative and GAD-negative; they generated only low mol. wt bands on $X b a \mathrm{I}$ PFGE analysis. When the $16 \mathrm{~S}$ rDNA of each ICDDRB strain was sequenced and compared with the type strain of $H$. alvei, ATCC $13337^{\mathrm{T}},>7.85 \%$ sequence divergence between each ICDDRB strain and ATCC $13337^{\mathrm{T}}$ was noted. The ICDDRB strains shared greatest $16 \mathrm{~S}$ rDNA sequence similarity to Escherichia/Shigella species following a search of the MicroSeq Database (Applied Biosystems, Foster City, CA, USA), further supporting the taxonomic relatedness of these organisms to Escherichia species. Strain 10790 was most closely related to $E$. coli and $S$. boydii $(1.33 \%$ sequence divergence with each species). Several additional differences were observed (Table 3) when the preformed enzymic properties of these five ICDDRB strains were compared to 13 typical $H$. alvei strains (including ATCC $13337^{\mathrm{T}}$, ATCC 29926 and ATCC 29927). H. alvei produced higher enzymic activities for both alkaline and acid phosphatase and leucine arylamidase than did ICDDRB strains. The latter were enzymically more active against substrates used to detect $\beta$-galactosidase and naphthol-AS-BI-phosphohydrolase activities. No ICDDRB or $H$. alvei isolate produced preformed C 4 or C 8 esterase, C 14 lipase, valine or cystine arylamidase, trypsin, chymotrypsin, $\alpha$-galactosidase, $\beta$-glucuronidase, $\beta$-glucosidase, $\mathrm{N}$ acetyl- $\beta$-glucosaminidase, $\alpha$-mannosidase or $\alpha$-fucosidase.

The pathogenic properties of ICDDRB strains were also compared with two classic $H$. alvei strains that are representative isolates (D46-NF, D67-NF) from two previously identified outbreaks of gastro-enteritis in Newfoundland attributed to $\mathrm{O} 3: \mathrm{H}^{-}$hafniae $[9,16]$. All seven strains were negative for Shiga toxin genes by PCR and failed to produce bacterial cytolysins or invade HEp-2 cells. The ICDDRB strains produced a weak localised adherence pattern in initial HEp-2 adhesion studies, but this adherence pattern was not reproducible in subsequent trials; neither strain D46-NF

Table 2. Comparison of ICDDRB strains to reference cultures of $H$. alvei

\begin{tabular}{|c|c|c|c|c|c|c|}
\hline Strain & $\begin{array}{l}\text { Biochemical } \\
\text { test results }\end{array}$ & $\begin{array}{l}\text { Lysis by phage } \\
1672\end{array}$ & phoE & GAD & PFGE (XbaI) & $\begin{array}{c}16 \mathrm{~S} \text { sequence } \\
\text { divergence }^{*}(\%)\end{array}$ \\
\hline ICDDRB 12502 & Atypical $^{\dagger}$ & - & + & + & Ladder & 7.86 \\
\hline ICDDRB 10790 & Atypical & - & + & + & Ladder & 7.95 \\
\hline ICDDRB 10457 & Atypical & - & + & + & Ladder & 7.86 \\
\hline ICDDRB 9194 & Atypical & - & + & + & Ladder & 7.95 \\
\hline ICDDRB 19982 & Atypical & - & + & + & Ladder & 7.95 \\
\hline H. alvei ATCC $13337^{\mathrm{T}}$ & Typical & + & - & - & Low mol. wt bands & 0 \\
\hline H. alvei ATCC 29926 & Typical & + & - & - & Low mol. wt bands & 0.09 \\
\hline H. alvei ATCC 29927 & Typical & + & - & - & Low mol. wt bands & 0.95 \\
\hline
\end{tabular}

phoE, outer-membrane protein gene; GAD, glutamate decarboxylase; PFGE, pulsed-field gel electrophoresis.

* Sequence divergence relative to ATCC $13337^{\mathrm{T}}$.

${ }^{\dagger}$ As previously defined [13]. 
Table 3. Enzymic activities of ICDDRB and $H$. alvei strains*

\begin{tabular}{lcc}
\hline \multirow{2}{*}{ Enzyme } & $\begin{array}{c}\text { Average relative activity for the following } \text { groups }^{\dagger} \\
\text { (percent of strains) }\end{array}$ \\
\cline { 2 - 3 } Alkaline phosphatase & $1.8(100)$ & $3.15(100)$ \\
Leucine arylamidase & $1.4(100)$ & $2.85(100)$ \\
Acid phosphatase & $2.4(100)$ & $3.76(100)$ \\
Naphthol-AS-BI-phosphohydrolase & $1.2(100)$ & $0.38(38)$ \\
$\beta$-Galactosidase & $2.2(100)$ & $0.92(62)$ \\
$\alpha$-Glucosidase & $0.4(20)$ & 0 \\
\hline
\end{tabular}

* As determined with the API ZYM strip.

${ }^{\dagger}$ As previously defined $\Sigma\left(n_{1} \ldots n_{\mathrm{x}}\right) / x$ [26].

nor strain D67-NF adhered to HEp-2 cells in a recognisable pattern. As previously reported, all five ICDDRB strains were eaeA-positive [13] but neither strain D46-NF nor strain D67-NF contained this gene. There was no appreciable difference in the mean LD50 values between the ICDDRB $\left(2.18 \times 10^{7}\right)$ and Newfoundland $\left(3.23 \times 10^{7}\right)$ strains.

\section{Enzymic studies and $16 S$ rDNA sequencing}

Twenty-two isolates representing different Barbe biotypes and carbohydrate fermentation patterns were selected for further analysis. All 22 isolates produced siderophores but lacked alkylsulphatase, cellulase, chitinase, deoxyribonuclease, elastase, lecithinase, mucinase, protease, ribonuclease, tyrosinase and stapholysin activities. Two DNA groups were demonstrated based upon the results of $16 \mathrm{~S}$ rDNA sequencing (Table 4). DNA group 1, which included the type strain ATCC $13337^{\mathrm{T}}$, consisted of five isolates $(<0.20 \%$ divergence). DNA group 2, represented by ATCC 29927, consisted of 17 isolates $(<0.10 \%$ divergence). The two
$\mathrm{O} 3: \mathrm{H}^{-}$strains associated with different outbreaks of diarrhoeal disease fell into different DNA groups based upon 16S rDNA sequencing. With the exception of Barbe biotype 1 and DNA group 2, Barbe or carbohydrate fermentation patterns were not linked specifically to either DNA group. Brenner [4] has previously suggested that motility at $24 \mathrm{~h}$ was the most useful phenotypic marker for recognising each DNA group. Only one $(20 \%)$ of five DNA group 1 isolates was motile at $24 \mathrm{~h}$ both in motility deep and chemotactic plate assays; for DNA group 2, 12 (71\%) of 17 isolates were motile. In this study malonate utilisation appeared to be a better marker as all DNA group 1 isolates were positive and only $2(12 \%)$ of 17 DNA group 2 isolates were positive.

\section{Discussion}

The results of this study indicate that the genus Hafnia as presently defined consists of members with fairly homogeneous phenotypic profiles. Testing a selected

Table 4. Characteristics of selected $H$. alvei strains by DNA group

\begin{tabular}{|c|c|c|c|c|c|c|c|c|}
\hline \multirow[b]{2}{*}{ Strain } & \multirow[b]{2}{*}{ DNA group } & \multicolumn{2}{|c|}{$16 \mathrm{~S}$ divergence $(\%)$ from } & \multirow[b]{2}{*}{ Biotype* $^{*}$} & \multicolumn{2}{|c|}{ Motility $(24 \mathrm{~h})$} & \multirow[b]{2}{*}{ Malonate } & \multirow[b]{2}{*}{ Other tests } \\
\hline & & ATCC 13337 & ATCC 29927 & & tube & plate $^{\dagger}$ & & \\
\hline$\overline{\mathrm{ATCC}} 13337^{\mathrm{T}}$ & 1 & 0 & 0.95 & 2 & + & 54 & + & $\mathrm{Ure}^{+}$ \\
\hline D46-NF & 1 & 0 & 0.95 & 1 & - & 12 & + & \\
\hline $131-004$ & 1 & 0.09 & 0.85 & 2 & - & 3 & $(+)$ & \\
\hline ATCC 29926 & 1 & 0.09 & 0.85 & 1 & - & 11 & + & \\
\hline HA 2 & 1 & 0.19 & 0.85 & 4 & - & 5 & + & \\
\hline ATCC 29927 & 2 & 0.95 & 0 & 1 & + & 80 & - & \\
\hline CCUG 429 & 2 & 0.95 & 0 & 1 & + & 80 & - & $\mathrm{Raf}^{+}$ \\
\hline HA 11 & 2 & 0.95 & 0 & 1 & + & 80 & - & \\
\hline HA 5 & 2 & 0.95 & 0 & 1 & - & 5 & - & \\
\hline D67-NF & 2 & 0.95 & 0 & 1 & + & 68 & - & \\
\hline 131-009 & 2 & 0.95 & 0 & 1 & + & 80 & - & $\mathrm{Lac}^{+}, \mathrm{Raf}^{+}$ \\
\hline HA 1 & 2 & 0.95 & 0 & 1 & - & 5 & - & \\
\hline HA 18 & 2 & 0.95 & 0 & 1 & + & 80 & - & \\
\hline HA 6 & 2 & 0.95 & 0 & 1 & + & 80 & + & \\
\hline HA 8 & 2 & 0.95 & 0 & 1 & - & 5 & - & \\
\hline HA 3 & 2 & 0.85 & 0.09 & 1 & - & 5 & - & \\
\hline $131-017$ & 2 & 0.85 & 0.09 & 1 & + & 40 & - & $\mathrm{Lac}^{+}, \mathrm{Raf}^{+}$ \\
\hline HA 10 & 2 & 0.85 & 0.09 & 1 & - & 4 & - & \\
\hline HA 4 & 2 & 1.04 & 0.09 & 1 & + & 34 & + & \\
\hline HA 17 & 2 & 1.04 & 0.09 & 1 & + & 80 & - & $\mathrm{Cel}^{+}$ \\
\hline HA 9 & 2 & 1.04 & 0.09 & 1 & + & 80 & - & \\
\hline HA 7 & 2 & 1.04 & 0.09 & 1 & + & 78 & - & \\
\hline
\end{tabular}

Ure, urease; Raf, raffinose; Lac, lactose; Cel, cellobiose.

* Barbe biotypes (see Table 1).

${ }^{\dagger}$ Zone of chemotactic migration (mm). 
group of $H$. alvei isolates for the production of extracellular enzymes by plate assays revealed uniformly negative results with the singular exception of siderophore production. Uniform production of a siderophore that is not related to enterobactin or aerobactin has recently been reported by Podschun et al. [28] in extra-intestinal isolates of H. alvei. Barbe, in 1969, described two biotypes of $H$. alvei based upon arbutin and aesculin hydrolysis and fermentation of salicin and D-arabinose [4]. Results from the present investigation indicate that at least four distinct biotypes can be detected based upon these four tests. Biotype 2, and two new biotypes 3 and 4 , constitute only $\sim 25 \%$ of the isolates tested. Likewise, unusual $H$. alvei fermentation patterns previously described by Gavini and others [27] account for $<10 \%$ of all isolates studied, similar to the findings of Greipsson and Priest [14] and Sakazaki and Tamura [2]. Thus, an easy biotyping system to subgroup strains of $H$. alvei implicated in human disease does not exist.

In agreement with previous studies $[12,13]$, the results of the present investigation provide further evidence that the ICDDRB strains of Albert and colleagues $[7,8]$ that have been implicated in diarrhoeal disease are not members of the genus Hafnia. ICDDRB strains produced glutamate decarboxylase, an activity only associated with E. coli and some Shigella strains in the family Enterobacteriaceae [18]. Furthermore, partial $16 \mathrm{~S}$ rDNA sequence data clearly indicate that all five ICDDRB strains are most closely related to Escherichia/Shigella and exhibit high sequence divergence ( $\sim 8 \%$ ) from the type strain for H. alvei, ATCC $13337^{\mathrm{T}}$.

True Hafnia strains - such as D46-NF and D67-NF, that were epidemiologically associated with outbreaks of gastro-enteritis - lacked the eaeA gene, and no other recognisable virulence factors that might play a causal role in bacterial diarrhoea were identified [29]. This indicates that there is no credible laboratory evidence at present to link $H$. alvei to individual case reports $[10,30]$ or outbreaks $[9,16]$ of diarrhoeal disease. Currently, $H$. alvei can only be considered a rare opportunist extra-intestinal pathogen in selected patient populations [6].

The results of $16 \mathrm{~S}$ rDNA sequencing of $22 \mathrm{H}$. alvei isolates support the findings of DNA pairing studies by Steigerwalt et al. [3] and Brenner [4] that two genomospecies exist within $H$. alvei. As ATCC $13337^{\mathrm{T}}$ is the type strain for $H$. alvei, DNA group 1 is by definition $H$. alvei sensu stricto. DNA group 2, which accounted for $17(77 \%)$ of the 22 isolates analysed in this study, represented the majority of clinical isolates. Brenner [4] found that no single test could accurately predict DNA group assignments for individual isolates. The single best discriminatory test in that study was motility at $24 \mathrm{~h}$, with $9 \%$ of DNA group 1 isolates and $100 \%$ of DNA group 2 isolates positive. However, in the present investigation, motility at $24 \mathrm{~h}$ did not yield as high a discriminatory value (20\% versus $71 \%$ ) as in the study of Brenner [4]. This may be due to the low number of group 1 isolates identified by $16 \mathrm{~S}$ rDNA sequencing $(n=5)$ or the deliberate selection of isolates with unusual phenotypic properties used in this study for sequence analysis. What is clear from the results shown in Table 4 is that neither Barbe biotypes nor distinct taxa as defined by Gavini et al. [27] based upon unusual sugar fermentation patterns correlates with presently defined DNA groups. Brenner [4] indicated that Hafnia DNA groups 1 and 2 could be phenotypically separated from one another by a battery of biochemical tests which included those tests suggested by Barbe plus inulin fermentation, sodium acetate utilisation and urease production. However, exact numbers of strains analysed with phenotype patterns were not provided. As seven or more tests appear to be necessary to define each DNA group, and there appears to be no clinical reason to warrant separation of the two genomospecies, $H$. alvei will continue to exist as a complex for the foreseeable future. However, further studies characterising the two genomospecies within Hafnia and their role in human disease seem warranted.

\section{References}

1. Møeller V. Distribution of amino acid decarboxylases in Enterobacteriaceae. Acta Pathol Microbiol Scand 1954; 35: 259-277.

2. Sakazaki R, Tamura K. The genus Hafnia. In: Balows A, Trüper HG, Dworkin M, Harder W, Schleifer K-H (eds) The prokaryotes, 2nd edn. Berlin, Springer-Verlag. 1991: 2816-2821.

3. Steigerwalt AG, Fanning GR, Fife-Asbury MA, Brenner DJ. DNA relatedness among species of Enterobacter and Serratia. Can J Microbiol 1976; 22: 121-137.

4. Brenner DJ. Introduction to the family Enterobacteriaceae. In: Starr MP, Stolp H, Trüper HG, Balows A, Schlegal HG (eds) The prokaryotes. Berlin, Springer-Verlag. 1981: 1105-1127.

5. Janda JM, Abbott SL. The genus Hafnia. In: The enterobacteria. Philadelphia, Lippincott-Raven. 1998: 322-335.

6. Günthard H, Pennekamp A. Clinical significance of extraintestinal Hafnia alvei isolates from 61 patients and review of the literature. Clin Infect Dis 1996; 22: 1040-1045.

7. Albert MJ, Alam K, Islam M et al. Hafnia alvei, a probable cause of diarrhea in humans. Infect Immun 1991; 59: $1507-1513$

8. Albert MJ, Faruque SM, Ansaruzzaman M et al. Sharing of virulence-associated properties at the phenotypic and genetic levels between enteropathogenic Escherichia coli and Hafnia alvei. J Med Microbiol 1992; 37: 310-314.

9. Ratnam S. Etiologic role of Hafnia alvei in human diarrheal illness. Infect Immun 1991; 59: 4744.

10. Reina J, Hervas J, Borrell N. Acute gastroenteritis caused by Hafnia alvei in children. Clin Infect Dis 1993; 16: 443.

11. Ridell J, Siitonen A, Paulin L, Mattila L, Korkeala H, Albert MJ. Hafnia alvei in stool specimens from patients with diarrhea and healthy controls. J Clin Microbiol 1994; 32: 2335-2337.

12. Ridell J, Siitonen A, Paulin L, Lindroos O, Korkeala H, Albert MJ. Characterization of Hafnia alvei by biochemical tests, random amplified polymorphic DNA PCR, and partial sequencing of $16 \mathrm{~S}$ rRNA gene. J Clin Microbiol 1995; 33: 2372-2376.

13. Janda JM, Abbott SL, Albert MJ. Prototypal diarrheagenic strains of Hafnia alvei are actually members of the genus Escherichia. J Clin Microbiol 1999; 37: 2399-2401.

14. Greipsson S, Priest FG. Numerical taxonomy of Hafnia alvei. Int J Syst Bacteriol 1983; 33: 470-475. 
15. Abbott SL, Cheung WKW, Kroske-Bystrom S, Malekzadeh T, Janda JM. Identification of Aeromonas strains to the genospecies level in the clinical laboratory. J Clin Microbiol 1992; 30: $1262-1266$

16. Ratnam S, Butler RW, March S et al. Enterobacter hafniaeassociated gastroenteritis - Newfoundland. Can Dis Wkly Rep 1979; 5: 231-232.

17. Guinée PAM, Valkenburg JJ. Diagnostic value of a Hafniaspecific bacteriophage. J Bacteriol 1968; 96: 564.

18. Rice EW, Johnson CH, Dunnigan ME, Reasoner DJ. Rapid glutamate decarboxylase assay for detection of Escherichia coli. Appl Environ Microbiol 1993; 59: 4347-4349.

19. Adler J. A method for measuring chemotaxis and use of the method to determine optimum conditions for chemotaxis by Escherichia coli. J Gen Microbiol 1973; 74: 77-91.

20. Janda JM, Abbott SL, Khashe S, Robin T. Biochemical investigations of biogroups and subspecies of Morganella morganii. J Clin Microbiol 1996; 34: 108-113.

21. Janda JM. Biochemical and exoenzymatic properties of Aeromonas species. Diagn Microbiol Infect Dis 1985; 3: 223-232.

22. Oliver JD, Wear JE, Thomas MB, Warner M, Linder $\mathrm{K}$. Production of extracellular enzymes and cytotoxicity by Vibrio vulnificus. Diagn Microbiol Infect Dis 1986; 5: 99-111.

23. Janda JM, Abbott SL, Woodward D, Khashe S. Invasion of HEp-2 and other eukaryotic cell lines by providenciae: further evidence supporting the role of Providencia alcalifaciens in bacterial gastroenteritis. Curr Microbiol 1998; 37: 159-165.

24. Khashe S, Scales DJ, Abbott SL, Janda JM. Non-invasive Providencia alcalifaciens strains fail to attach to HEp-2 cells. Curr Microbiol 2001; 43: 414-417.

25. Janda JM, Kokka RP. The pathogenicity of Aeromonas strains relative to genospecies and phenospecies identification. FEMS Microbiol Lett 1991; 90: 29-34.

26. Janda JM, Abbott SL, Khashe S, Probert W, Biochemical identification and characterization of DNA groups within the Proteus vulgaris complex. J Clin Microbiol 2001; 39: $1231-1234$.

27. Gavini F, Ferragut C, Lefebre B, Leclerc H. Étude taxonomique d'entérobactéries appartenant ou apparentées au genre Enterobacter. [Taxonomic study of enterobacteria belonging or related to the genus Enterobacter.] Ann Microbiol 1976; 127B: $317-335$.

28. Podschun R, Fischer A, Ullmann U. Characterisation of Hafnia alvei isolates from human clinical extra-intestinal specimens: haemagglutinins, serum resistance and siderophore synthesis. $J$ Med Microbiol 2001; 50: 208-214.

29. Seral C, Castillo FJ, Llorente MT et al. The eaeA gene is not found in Hafnia alvei from patients with diarrhea in Aragon, Spain. Int Microbiol 2001; 4: 81-82.

30. Westblom TU, Milligan TW. Acute bacterial gastroenteritis caused by Hafnia alvei. Clin Infect Dis 1992; 14: 1271-1272. 